\title{
Characteristics of decadal-centennial-scale changes in East Asian summer monsoon circulation and precipitation during the Medieval Warm Period and Little Ice Age and in the present day
}

\author{
ZHOU XiuJi ${ }^{1}$, ZHAO Ping $^{2 *}$, LIU Ge $^{1} \&$ ZHOU TianJun ${ }^{3}$ \\ ${ }^{1}$ State Key Laboratory of Severe Weather, Chinese Academy of Meteorological Sciences, Beijing 100081, China; \\ ${ }^{2}$ National Meteorological Information Centre, Beijing 100081, China; \\ ${ }^{3}$ The State Key Laboratory of Numerical Modeling for Atmospheric Sciences and Geophysical Fluid Dynamics, Institute of Atmospheric Physics, \\ Chinese Academy of Sciences, Beijing 100029, China
}

Received March 2, 2011; accepted June 13, 2011

\begin{abstract}
Using meteorological observations, proxies of precipitation and temperature, and climate simulation outputs, we synthetically analyzed the regularities of decadal-centennial-scale changes in the summer thermal contrast between land and ocean and summer precipitation over the East Asian monsoon region during the past millennium; compared the basic characteristics of the East Asian summer monsoon (EASM) circulation and precipitation in the present day, the Little Ice Age (LIA) and the Medieval Warm Period (MWP); and explored their links with solar irradiance and global climate change. The results indicate that over the last 150 years, the EASM circulation and precipitation, indicated by the temperature contrast between the East Asian mainland and adjacent oceans, had a significant decadal perturbation and have been weaker during the period of rapid global warming over the past 50 years. On the centennial time scale, the EASM in the MWP was strongest over the past 1000 years. Over the past 1000 years, the EASM was weakest in 1450-1570. When the EASM circulation was weaker, the monsoon rain belt over eastern China was generally located more southward, with there being less precipitation in North China and more precipitation in the Yangtze River valley; therefore, there was an anomalous pattern of southern flood/northern drought. From the 1900s to 1920s, precipitation had a pattern opposite to that of the southern flood/northern drought, with there being less precipitation in the Yangtze River valley and more precipitation in North China. Compared with the case for the MWP, there was a longer-time-scale southern flood/northern drought phenomenon in 1400-1600. Moreover, the EASM circulation and precipitation did not synchronously vary with the trend of global temperature. During the last 150 years, although the annual mean surface temperature around the world and in China has increased, the EASM circulation and precipitation did not have strengthening or weakening trends. Over the past 1000 years, the weakest EASM occurred ahead of the lowest Northern Hemispheric temperature and corresponded to the weakest solar irradiance.
\end{abstract}

Medieval Warm Period, Little Ice Age, present climate, East Asian monsoon, decadal-centennial-scale variability

Citation: Zhou X J, Zhao P, Liu G, et al. Characteristics of decadal-centennial-scale changes in East Asian summer monsoon circulation and precipitation during the Medieval Warm Period and Little Ice Age and in the present day. Chinese Sci Bull, 2011, 56: 3003-3011, doi: 10.1007/s11434-011-4651-4

Studies on the characteristics and regularities of climate change in the past millennium have received extensive attention. Such studies have emphasized three important periods: the Medieval Warm Period (MWP), the Little Ice Age (LIA) and the Current Warm Period (CWP). In the last 10 years, there has been great progress in research on historical climate changes in China [1-11]. Time series of historical

*Corresponding author (email: zhaop@cma.gov.cn) climate changes in China have been reconstructed, with the length of some series being 1000 years or more. Moreover, characteristics of millennium climate changes in China have been revealed. These results have shown that precipitation has had a pronounced centennial-scale variation in China and phenomena such as the MWP and LIA possibly occurred in the Chinese region. The climate was warmer during the Sui and Tang dynasties and cooler during the Song dynasty. During the MWP, the climate was wetter in North 
China and drier to the south of the Yangtze River, while during the LIA, there was a drier climate in North China and a wetter climate to the south of the Yangtze River. Moreover, air temperatures in eastern China from the second half of the 9th century to the 11th century and in the 13th century were comparable to or slightly lower than those in the present $[12,13]$. These results greatly enrich our understanding of features of long-term variations of the East Asian summer monsoon (EASM) climate.

Because the Chinese climate is largely under the influence of the East Asian monsoon circulation and an anomaly of the monsoon activity often causes severe droughts or floods, studying the long-term variation trends of the East Asian monsoon is important to understanding the mechanisms responsible for climate change and predicting its variation trends. Research has showed that summer precipitation significantly increased over the Horqin Sandy Land of northeastern China during the MWP, generally indicating a stronger EASM in that period [14]. In the case of the present climate, however, the EASM has weakened with the rapid warming of the global climate since the late 1970s, which led to an increase in precipitation in the Yangtze River valley and a decrease in precipitation in North China and a feature of southern flood/northern drought [15-19].

In the present study, we synthetically used meteorological observations, proxies of precipitation and temperature, climate simulation outputs and previous results; analyzed the regularities of decadal- and centennial-scale variations in the EASM thermal contrast and precipitation during the recent millennium; and revealed the basic characteristics of EASM circulation and precipitation during the present, LIA and MWP and their links with solar irradiance and global climate change.

\section{Choice of EASM index and introduction of data}

\subsection{Asian-Pacific Oscillation index}

The Asian monsoon is driven by the thermal difference between the Asian mainland and the adjacent oceans and has two basic characteristics. One is a change in the low-tropospheric wind direction under the influence of a seasonal variation in the thermal contrast and the other is the alternation between wet and dry seasons that corresponds to a variation in the wind. Thus, some authors have defined monsoon onset dates using a remarkable change in the prevailing wind or rainfall exceeding a certain level [20-24]. Additionally, other authors have used thermal contrast to indicate variations in the Asian monsoon circulation and precipitation [25-28].

A difference in the tropospheric thermal contrast between the Asian mainland and the Pacific can be described by the Asian-Pacific Oscillation (APO) index [28], which has a correlation coefficient of $0.93(0.81)$ with the zonal (meridional) difference in tropospheric temperature between East
Asia and the extratropical North Pacific (tropical western Pacific) during 1958-2001 [29]. Because the APO index is calculated from atmospheric elements over key areas, it may better indicate the varying characteristics of atmospheric circulation. For example, on interannual and decadal time scales, when the summer thermal contrast between Asia and the Pacific is stronger (weaker), the low-level low-pressure system over the Asian mainland is stronger (weaker), the upper-tropospheric South Asian high and low-level subtropical high over the western North Pacific are more northwards (southwards) in position, and there are low-level stronger (weaker) southwesterly winds over the monsoon region of eastern China $[28,30]$. Moreover, the APO index can reflect interannual-, decadal-, centennial-, and millennium-scale variations in monsoon precipitation over eastern China [28-33].

\subsection{Data}

The time series of the summer APO index for the last 100 years is taken from the reconstruction of Liu et al. [33]. Because recordings of meteorological gauge precipitation data were sparse in China before 1950 and their continuity has been poor in time, we analyzed the features of precipitation variations prior to 1950 using grid precipitation analysis data (from 1901) of the Climatic Research Unit (CRU) [34] and precipitation recorded at about 700 Chinese surface meteorological stations after 1950. Moreover, the 20th Century Reanalysis V2 products of the Earth System Research Laboratory of the National Oceanic and Atmospheric Administration (United States) prior to 1950 [35] were used in the present study because they may reflect features of the decadal variation in atmospheric circulation [31].

A longer time series of the APO index is taken from the reconstruction of Zhou et al. [30]. Its variation is consistent with that of the summer APO index reconstructed from the tree-ring width in Sha County, Fujian Province [36] during 1803-2006. The coupled climate system model FGOALS_gl developed by the State Key Laboratory of Numerical Modeling for Atmospheric Sciences and Geophysical Fluid Dynamics, Institute of Atmospheric Physics, Chinese Academy of Sciences [37] was used to simulate the longer-term change of the summer APO index over past millennium [38] and the simulated APO was compared with the reconstruction of Zhou et al. [30]. The external forcing data used in the model are taken from the reconstructions of Ammann et al. [39] and include the effects of solar activity and volcanic eruption on effective solar radiation and greenhouse gases. Moreover, sulfate aerosol changes during 1870-1999 were also taken into account. Studies have showed that a coupled model driven by these specified external forcing agents can reasonably capture major climatic characteristics of the MWP and LIA $[38,40]$. The definition of the model APO index is consistent with that of Zhao et al. [28]; that is,

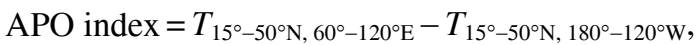


where $T$ is the tropospheric 500-200 $\mathrm{hPa}$ mean temperature.

We also used reconstructed solar irradiance [41], Northern Hemispheric annual mean surface air temperatures [42] during the past millennium, and time series of 950-1999 drought-flood grades over the Yellow River valley and southern China [43] and 500-year drought-flood grades over China [44] reconstructed from Chinese historical documents.

\section{Basic characteristics of East Asian monsoon precipitation in the last 1000 years}

\subsection{Decadal oscillation of East Asian monsoon circula- tion and precipitation over the last 150 years}

Figure 1 shows the time series of the summer APO index reconstructed from sea-level pressure by Liu et al. [33]. In the figure, the APO index has pronounced decadal variability. It tended to a positive value from the 1880 s to mid1890 s, from the mid-1910s to 1920 s, and from the 1940 s to 1970s, corresponding to a strong thermal contrast between East Asia and the Pacific, while it tended to a negative value from the 1850 s to early 1870 s, the late 1890 s to early 1910 s, and the 1980 s to 1990 s, corresponding to a weak thermal contrast between East Asia and the Pacific.

Corresponding to the characteristics of decadal variations of the summer thermal contrast between East Asia and the adjacent oceans in the early 20th century, atmospheric circulation and precipitation over the East Asian monsoon region had significant anomalies on the decadal time scale. The EASM is usually characterized by lower-tropospheric prevailing southwesterly winds over East Asia, and the monsoon precipitation over eastern China is in front of the maximum southwesterly wind centers [27]. Thus, the prevailing southwesterly winds are stronger (weaker) over eastern China and advance northwards to a higher latitude (stay in southern China) when the EASM circulation is stronger (weaker). An anomalous southerly (northerly) wind prevailing over eastern China often results in a more northward (southward) monsoon rain belt over eastern China

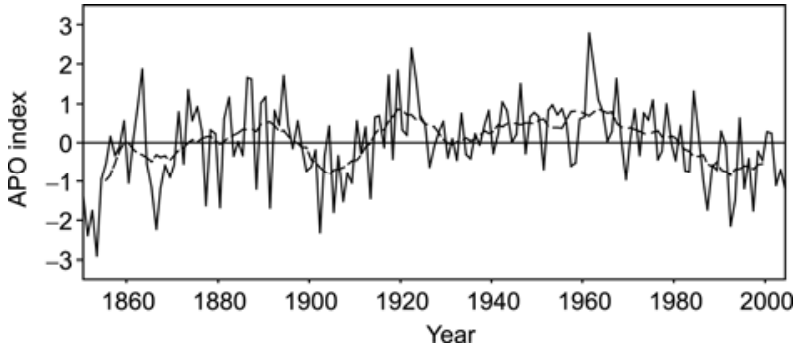

Figure 1 Summer APO index (solid line) reconstructed from sea-level pressure and its 11-year running average (dashed line) during 1850-2004 [33]. The $x$-axis is the year and the $y$-axis is the anomaly value of the APO index.

$[19,45]$. Figure 2(a) shows the composite difference of the summer 850-hPa flow field between the periods 1921-1930 (with a higher APO index) and 1901-1910 (with a lower APO index). It is seen that a southwesterly flow prevailed over the eastern Arabian Sea, the Indian Peninsula, the Bay of Bengal, southwestern China, and the southern part of North China, indicating a stronger southwesterly flow over these regions during 1921-1930 than during 1901-1910; that is, the EASM was stronger, which favors a more northward rain belt. Meanwhile, there was an anomalous cyclonic circulation over the eastern part of North China and the southern part of Northeast China, favoring the strengthening of local precipitation, while there was anomalous anticyclonic circulation over southern China, not favoring precipitation. It is seen from the composite difference of CRU summer precipitation between these two decades (Figure 2(b)) that there were positive differences over central and eastern parts of North China, indicating an increase in precipitation in 1921-1930 relative to 1901-1910, while there were negative differences over the central and lower valleys of the Yangtze River, with a central value of $-150 \mathrm{~mm}$, indicating a decrease in precipitation in 19211930 relative to 1901-1910. This pattern of anomalous precipitation reflects a more northward monsoon rain belt in eastern China.

There were similar features in recent decades. Figure 3(a) shows the composite difference in the summer $850-\mathrm{hPa}$
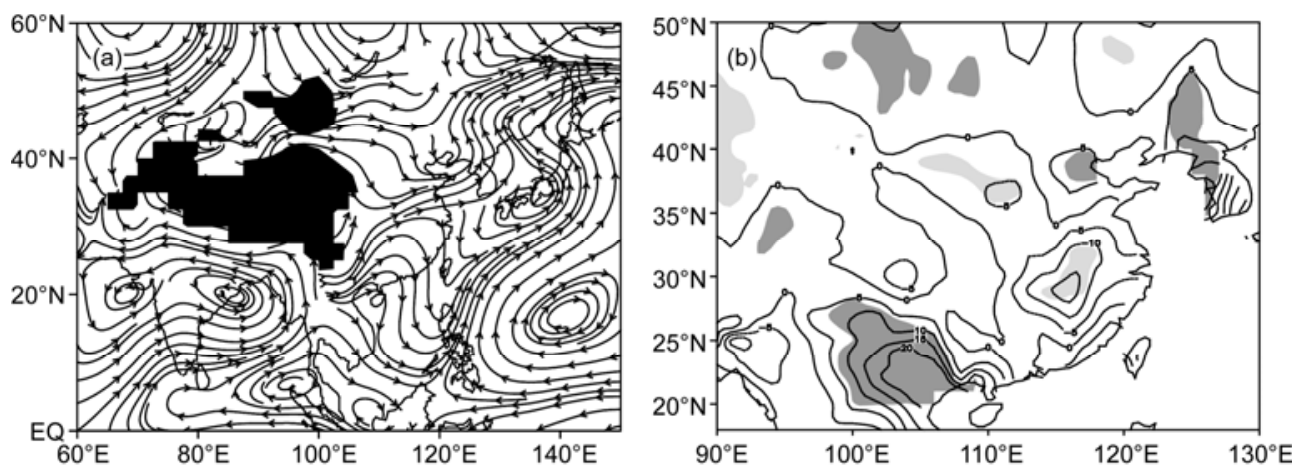

Figure 2 (a) Composite difference in the summer 850-hPa flow field between the periods 1921-1930 and 1901-1910; (b) same as (a) but for CRU precipitation $(\times 10 \mathrm{~mm}$; the shaded areas are significant at the $90 \%$ confidence level). 

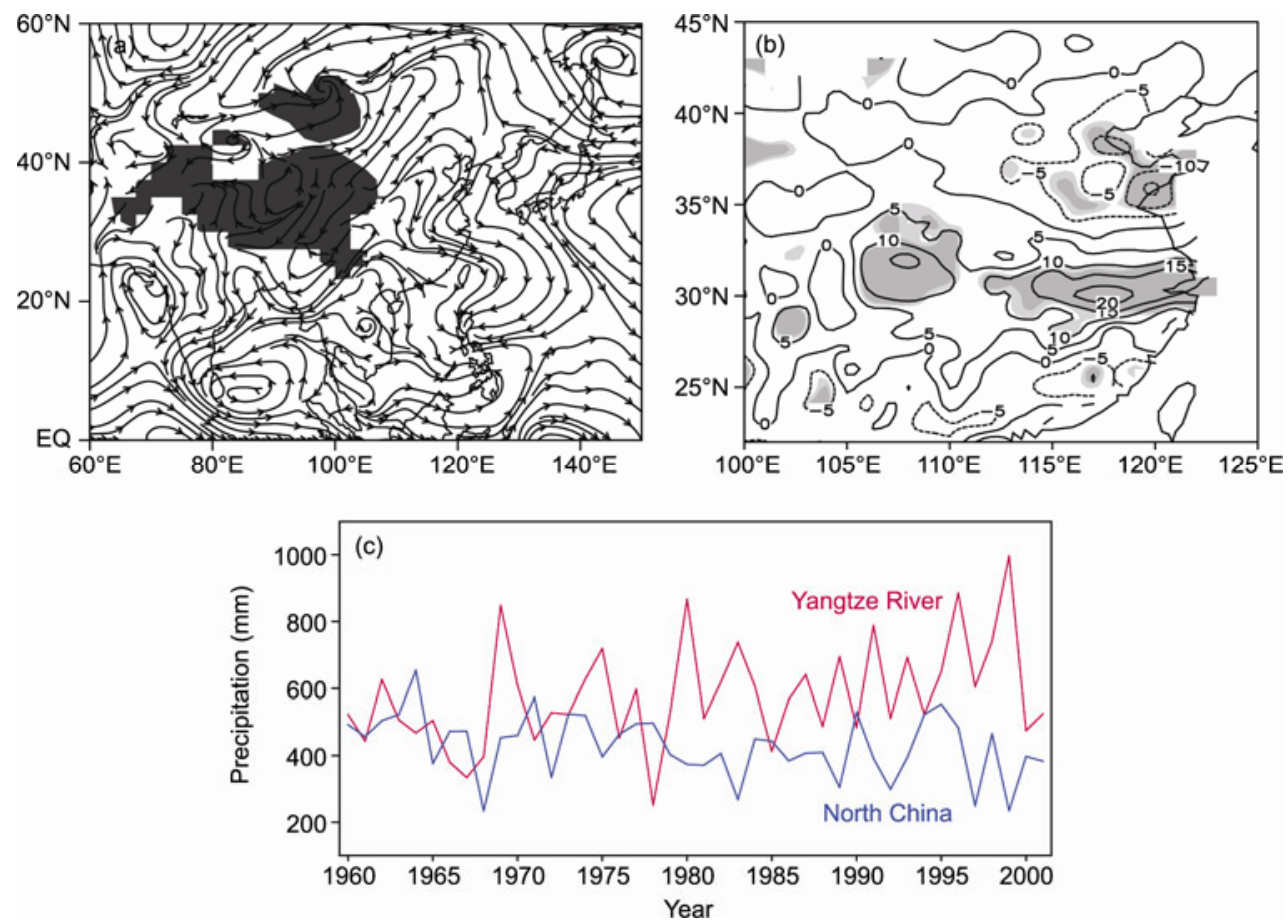

Figure 3 (a) Composite difference in the summer 850-hPa flow field between the periods 1980-1999 and 1960-1979 [17]; (b) same as in (a) but for summer total precipitation $(\times 10 \mathrm{~mm}$; the shaded areas are significant at the $90 \%$ confidence level) [17]; (c) temporal curves of summer total precipitation over the Yangtze River valley (over $29^{\circ}-32^{\circ} \mathrm{N}, 115^{\circ}-120^{\circ} \mathrm{E}$; red) and the central-eastern part of North China (over $35^{\circ}-40^{\circ} \mathrm{N}, 115^{\circ}-120^{\circ} \mathrm{E}$; blue) during 1961-2001, where the $x$-axis is the year and the $y$-axis is the precipitation value.

flow field between the periods 1980-1999 (with a lower APO index) and 1960-1979 (with a higher APO index) [17]. In the figure, an anomalous northeasterly flow prevailed over the Indian Peninsula, the Bay of Bengal, southwestern China, and the eastern part of North China, indicating a weaker summer southwesterly flow over these regions from the 1980 s to 1990 s than from the 1960 s to 1970 s, not favoring a northward advance of the monsoon rain belt over eastern China but resulting in a southward rain belt. Moreover, there was anomalous anticyclonic circulation over northern China, weakening the local precipitation, while there was anomalous cyclonic circulation over the Yangtze River, favoring stronger precipitation. Figure 3(b) shows the composite difference in summer precipitation recorded at surface meteorological stations between these two decades. There were significant positive differences over the Yangtze River and negative differences over North China [17]. In the temporal curve (Figure 3(c)), the mean value of summer total precipitation was $464 \mathrm{~mm}$ over North China and $500 \mathrm{~mm}$ over the Yangtze River valley in the 1960s, which are comparable. From the 1980 s to 1990 s, however, summer precipitation significantly increased over the Yangtze River valley and decreased over North China, showing the phenomenon of southern flood/northern drought $[15,16,46]$.

From the foregoing analysis, we note that although significant decadal anomalies of precipitation during the earlier period of the 20th century (Figure 2(b)) were smaller in area than those of recent decades (Figure 3(b)), the coupled links among ocean-land thermal contrast, atmospheric circulation, and precipitation over the East Asian monsoon region are generally consistent between these two periods and also consistent with those on the interannual time scale [28].

\subsection{Centennial-scale fluctuation of the EASM and precipitation during the LIA}

Figure 4(a) shows the 31-year running mean series of the reconstructed summer APO index [30]. In the figure, the APO index was generally weak and mainly negative during the LIA. Particularly, it was in a persistent negative phase during 1420-1625, reaching a minimum during 1450-1570 and corresponding to the weakest thermal contrast over the East Asian monsoon region during the past 1000 years.

To further verify the reliability of the decadal variability of the reconstructed APO index, the time series of the APO index over the past millennium simulated by FGOALS_gl is shown in Figure 4(b) [38]. It is seen that the simulated APO index entered into a persistent negative phase from the year 1400 , and apart from a break during 1500-1520, the negative APO index persisted until 1625. The APO index in this period was the weakest over the past 1000 years. It is evident that on the centennial time scale, the variability of the simulated was generally consistent with the variability of the APO index reconstructed by Zhou et al. [30]. Correlation analysis further showed that the correlation coefficient between the model and reconstruction during 1000-1985 is 

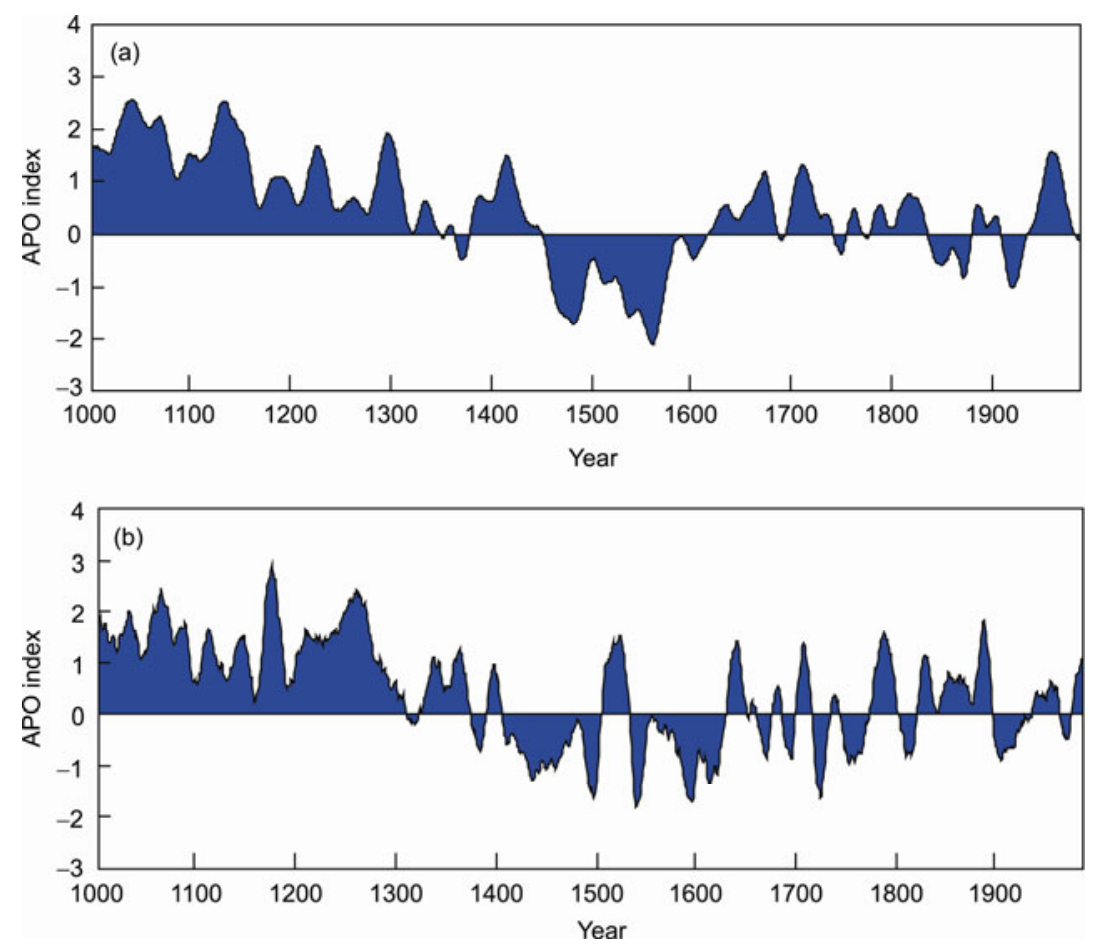

Figure 4 (a) The 31-year running mean normalized series of the reconstructed summer APO index [30] during 1000-1985; (b) same as in (a) but for the APO index simulated by the FGOALS_gl model [38]. The $x$-axis is the year and the $y$-axis is the APO value.

0.50 (significant at the $99.9 \%$ confidence level). This consistency between the simulated and reconstructed APO indices also implies the reliability of the centennial-scale variability of the APO index reconstructed by Zhou et al. [30]; in other words, over the last 1000 years, the thermal contrast between ocean and land over the East Asian monsoon region was weakest during 1450-1570, indicating a persistent weaker EASM. After 1650, the reconstructed and simulated APO indices fluctuated near zero and were mainly positive.

Corresponding to the persistent weaker thermal contrast over East Asia during 1400-1625, it may be guessed from studies on the present climate that during that period, southwesterly winds were weaker over eastern China and the monsoon rain belt was more southward, with there being more precipitation over the Yangtze River valley and less precipitation over North China. This guessed anomalous pattern is verified using precipitation proxies. Figure 5 shows the time series of flood frequency anomalies over the Yellow River valley and southern China in the warm season (May-September) in 10-year intervals during 991-1999 derived from historical documents [43]. In the figure, the flood frequency was small over the Yellow River valley during 1400-1600, with a mean value of 1.15 floods/10 years, and was smallest over the past 1000 years, indicating less precipitation over this valley. Meanwhile, the flood frequency was large over southern China, with a mean value of 2.45 floods/ 10 years, and was the largest on the 200-year scale over the past 1000 years, indicating more precipitation. The flood frequency was remarkably higher (lower) over the Yellow River valley (southern China) after 1650 than in the earlier LIA, indicating an anomalous precipitation pattern with more precipitation over North China and less precipitation over southern China, which corresponds to the stronger thermal contrast over the East Asian monsoon region in that period.

In the following section, the reconstructed warm-season (May-September) dry-wet index $\left(I_{\mathrm{DW}}\right)$ for 1470-1999 was used to further explore horizontal characteristics of precipitation over eastern China for strong and weak East Asian thermal contrasts; $I_{\mathrm{DW}}$ has five scales, namely 1 for flooding, 2 for slight flooding, 3 for normal conditions, 4 for slight drought, and 5 for drought [44]. Thus, precipitation is less when $I_{\mathrm{DW}}$ is higher. Figure 6 shows the composite difference in $I_{\mathrm{DW}}$ between the periods 1621-1740 (with a higher APO index) and 1470-1620 (with a lower APO index). In this figure, there were negative differences in the middle and lower valleys of the Yellow River and positive differences in the lower valley of the Yangtze River. This anomalous pattern shows that compared with the case for the period 1470-1620, there were fewer droughts or more floods (i.e. more precipitation) over the Yellow River valley and more droughts or fewer floods (i.e. less precipitation) over the Yangtze River valley during 1621-1740.

\subsection{Stronger EASM circulation in the MWP}

Compared with the case for the LIA, the APO was generally positive during 1000-1300 and was highest during 

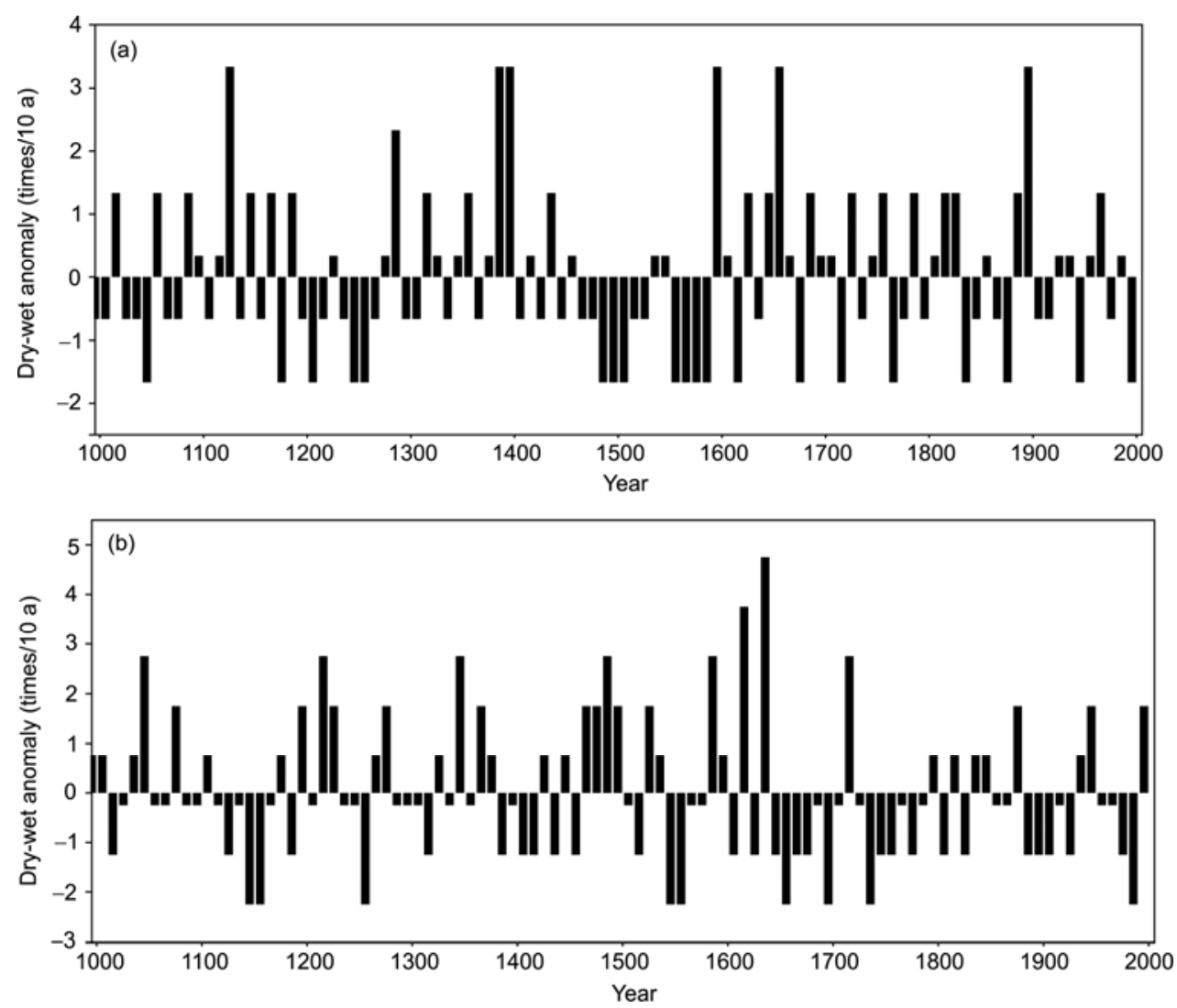

Figure 5 Time series of flood frequency anomalies over (a) the Yellow River valley and (b) southern China in the warm season (May through September) in 10-year intervals during 991-1999. The $x$-axis is the year and the $y$-axis is the flood frequency anomaly.

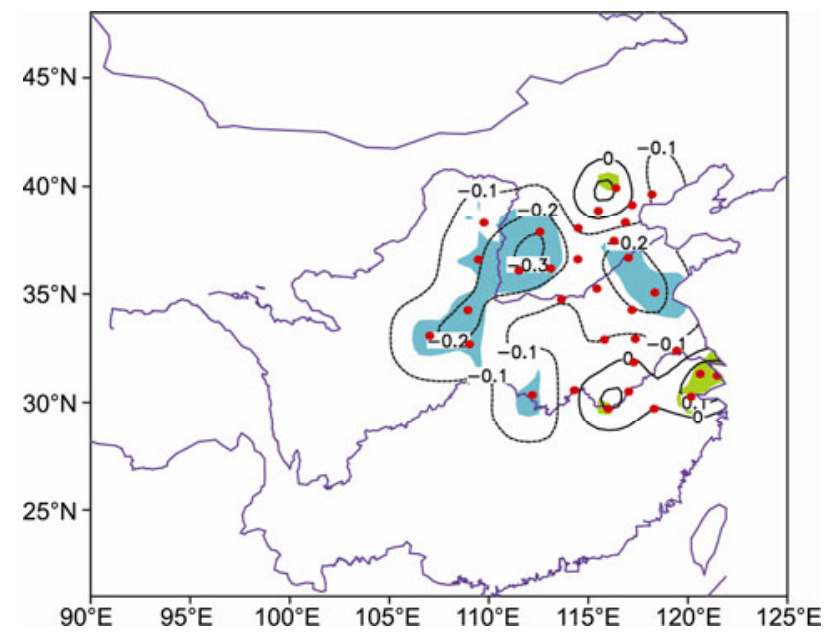

Figure 6 Composite difference in $I_{\mathrm{DW}}$ between periods with high (16211740) and low (1470-1620) APO indices (high minus low; red dots denote positions of the $I_{\mathrm{DW}}$ sites), shaded areas are at the $90 \%$ confidence level [30].

1000-1230 (Figure 4(a)), indicating a stronger summer thermal contrast between Asia and the adjacent oceans. This feature is seen in the time series of the APO index in the FGOALS_gl model output (Figure 4(b)); that is, the model APO index was also persistently positive during this period. Thus, on a centennial scale, the variability of the model
APO index is generally consistent with the APO index reconstructed by Zhou et al. [30] in the MWP. Corresponding to the stronger EASM circulation in the MWP, the monsoon rain belt over eastern China was usually more northwards, with there being less precipitation over southern China and more precipitation over North China. Figure 5 shows evidence of this anomalous precipitation pattern. As shown in the figure, during 1000-1200, the mean value of the flood frequency anomaly was 1.84 floods/10 years over the Yellow River valley, significantly higher than the value for the LIA, while it was 2.16 floods/10 years over southern China, less than in the LIA. This result indicates more precipitation over North China and less precipitation over southern China in the MWP.

Some geological evidence also supports more (less) precipitation over North China (the Yangtze River valley) in the MWP. For example, a high-resolution pollen record from the Mali Bog section indicated that summer precipitation remarkably increased in the Korqing Sandy Land of northeastern China during 975-1290 [14]; paleosol and lacustrine sediment in the Otindag Sandy Land of Inner Mongolia indicated that there was more precipitation over this region during 1000-1400 [47]; a lacustrine core taken from Daihai Lake in Inner Mongolia also indicated that there was more precipitation during 1020-1260, the level of Daihai lake gradually rose, and the climate was warm and 
wet [48]; $\mathrm{Wu}$ et al. [49] integrated evidence from paleosol, sporopollen, and lacustrine sediment and further revealed that during 600-1400, paleosol or lacustrine sediment developed well in a large area of North China, drifting sands were fixed, sandy land areas were small, vegetation cover increased and sandy land turned into dry steppe and woodland steppe, which indicate a warm and wet climate over North China at that time. For the Yangtze River valley, on the basis of a 3000-year precipitation curve reconstructed from diatom and sporopollen data for Longgan Lake $\left(29^{\circ} 50^{\prime}-\right.$ $30^{\circ} 05^{\prime} \mathrm{N}, 115^{\circ} 55^{\prime}-116^{\circ} 20^{\prime} \mathrm{E}$ ), Tong et al. [50] showed that the local climate was drier during most of the MWP (840-1000 and 1100-1300).

\section{Discussion and conclusion}

Asian monsoons are driven by a difference in the atmospheric response to the Asian mainland and adjacent oceans. In this study, we used an index of the temperature difference between land and ocean (namely the APO index) over the Asian monsoon region to determine variability in the EASM circulation and analyzed long-term variations in the EASM circulation and precipitation over the recent millennium by synthesizing meteorological observations, proxies of precipitation and temperature, and climate model output. The results are as follows.

(1) Over the past 100 years, the EASM circulation indicated by the APO index had a fluctuating feature on a decadal scale. The EASM was stronger in the mid-1910s to 1920s and the 1940s to 1970 s, with there being stronger southwesterly flow over eastern China, and there were anomalous cyclonic and anticyclonic circulations over the eastern part of North China and to the south of the Yangtze River, respectively. The EASM circulation was weaker in the late 1890 s to early 1910 and the 1980 s to 1990 s, and there were anomalous cyclonic and anticyclonic circulations over the Yangtze River valley and North China, respectively. Accordingly, relative to the 1900s, there was less precipitation over the Yangtze River valley and more precipitation over the eastern part of North China during the 1920s; relative to the 1960 s to 1970 s, there was more precipitation over the Yangtze River valley and less precipitation over the eastern part of North China from the 1980s to 1990s, showing the phenomenon of southern flood/northern drought, which has received extensive attention.

(2) The thermal contrast between ocean and land over the East Asian monsoon region during 1450-1570 was weakest over the past 1000 years, corresponding to weak EASM circulation. At this time, the EASM rain belt remained mainly over the Yangtze River valley, with there being less precipitation over North China. Afterwards, the EASM circulation slightly strengthened, with there being more precipitation over North China and less precipitation over southern China. In the MWP, the thermal contrast between land and ocean was generally stronger, which corresponded to stronger EASM circulation, with there being more precipitation over North China and less precipitation over southern China. This centennial-scale linkage between the East Asian monsoon and precipitation determined from proxies is basically consistent with that determined from present observations on interannual or decadal time scales, which implies that the centennial-scale linkage in this study may be supported physically and is reliable.

(3) For the past 1000 years, on the centennial scale, when thermal contrast between ocean and land over the East Asian monsoon region was weaker, monsoon precipitation over eastern China generally had a feature of opposite phases for southern and northern parts; that is, when there was less precipitation over North China, there was more precipitation over the middle and lower valleys of the Yangtze River. This phenomenon is similar to the southern flood/northern drought pattern during the last 50 years. In the 20th century, on the decadal scale, the earliest out-ofphase variation in precipitation between the southern and northern parts occurred from the 1900 s to 1920 s, having a pattern of precipitation opposite to the southern flood/northern drought pattern (namely a southern drought/northern flood pattern). On the centennial scale, the latest remarkable pattern of southern drought/northern flood occurred from the weakest EASM period to the subsequent increasing period in the LIA. Compared with the case in the MWP, there was a longer-time-scale phenomenon of southern flood/northern drought during 1420-1625. These results show that a positive or negative pattern of the southern flood/northern drought is probably one of major monsoon precipitation anomalous modes over eastern China. Whether this anomalous mode will occur in future decades, centuries, and millennia requires investigation.

We also noted that the annual mean surface air temperature over China had an increasing trend with an increase in the global annual mean surface temperature over the last 150 years [10]. However, thermal contrast and precipitation over the East Asian monsoon region had decadal fluctuation (shown in Figure 1) rather than a consistently increasing or decreasing trend. It is seen from the temporal curve of the Northern Hemispheric annual mean air temperature reconstructed by Mann et al. [42] that the lowest temperature over the past 1000 years occurred around 1700, more than 100 years after the weakest EASM. The thermal contrast between ocean and land over the East Asian monsoon region was stronger in the MWP than in the CWP, with there being more precipitation over North China and less precipitation over southern China, while this thermal contrast was weaker and opposite from the 1980s to 1990s when warming was rapid, that is, there was less precipitation over North China and more precipitation over southern China in the late peoiod. These results suggest asynchrony between the variation trends in the global and Northern Hemispheric air temperatures and the intensity of the EASM circulation and 


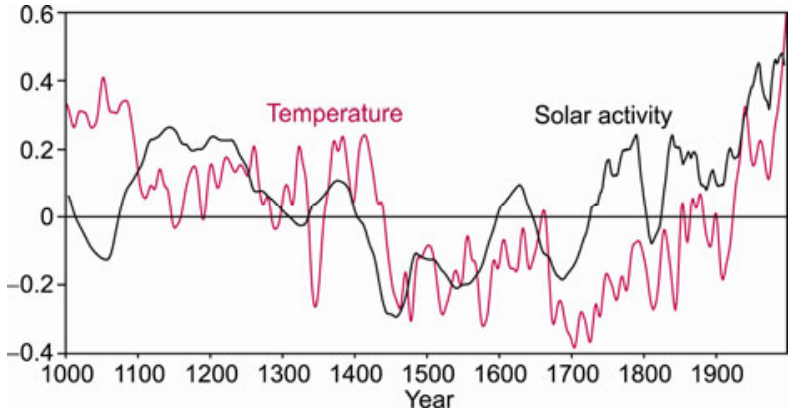

Figure 7 Temporal curves of the nine-year running mean values of the 1000-1985 Northern Hemispheric annual mean surface air temperature and solar irradiance, where the $x$-axis is the year and the $y$-axis is the air temperature and solar irradiance.

precipitation. From the variation curve (Figure 7) of the solar irradiance over 1000 years reconstructed by Bard et al. [41], it is seen that solar irradiance was weakest over the past 1000 years during 1420-1625, corresponding to the weakest ocean-land thermal contrast over the East Asian monsoon region. This result likely reflects the effect of solar activity on the thermal contrast over the Asian monsoon region on the centennial scale [51]. Therefore, when analyzing characteristics of regional climate with the background of global climate change, we should take into account other elements indicating comprehensive climatic features such as atmospheric circulation and precipitation over monsoon regions. Although both the MWP and CWP have climate backgrounds of global warming, the East Asian monsoon intensity and precipitation are remarkably different in these two warm periods. Further research is required to investigate whether this difference is associated with different forcing factors in these two periods.

This work was supported by the National Natural Science Foundation of China (40890053 and 40890052), the National Basic Research Program of China (2007CB815901), and the Special Project of Basic Science and Technology (2011FY120300).

1 Zhu K Z. Preliminary research on climatic variation in China over the recent 5000 years (in Chinese). Sci China, 1973, 3: 168-189

2 Zheng J Y, Zheng S Z. An analysis on cold/warm and dry/wet in Shandong Province during historical times (in Chinese). Acta Geogr Sin, 1993, 48: 348-357

3 Yao T D. Climatic and environmental record in the past about 2000 years from the Guliya ice core (in Chinese). Quat Sci, 1997, 17: 52-61

4 Yang B, Shi Y F, Li H P. Some advances in climatic change over the past two millennia (in Chinese). Adv Earth Sci, 2002, 17: 110-117

5 Yang B, Braeuning A. Temperature variations on the Tibetan Plateau during the last millennium (in Chinese). Adv Clim Change Res, 2006, 2: 104-107

6 Ge Q S, Zheng J Y, Man Z M, et al. Reconstruction and analysis on the series of winter-half-year temperature changes over the past 2000 years in eastern China (in Chinese). Earth Sci Front, 2002, 9: 169-181

7 Ren G Y, Chun Z Y, Zhou Y Q, et al. Recent progresses in studies of regional temperature changes in China (in Chinese). Clim Environ Res, 2005, 10: 701-716

8 Li M Q, Jin H L, Zhang H. Advances of climate research in the Little
Ice Age (in Chinese). J Desert Res, 2005, 25: 731-737

9 Wang S W, Ye J L, Gong D Y. Climate in China during ice age. Quat Sci, 1998, 18: 54-64

10 Wang S W. Chinese climate changes. In: Qin D H, ed. Evolution and Prediction of Climate and Environment in Evolution of Chinese Climate and Environment (Vol. One) (in Chinese). Beijing: Science Press, 2005. 63-103

11 Zhang D, Liu Y W. A new approach to the reconstruction of temporal rainfall sequences from 172401904 Qing Dynasty weather records for Beijing (in Chinese). Quat Sci, 2002, 22: 199-208

12 Wang S W, Gong D Y. China temperature in several characteristic periods of the Holocene (in Chinese). Prog Nat Sci, 2000, 10: 325-332

13 Wang S W, Wen X Y, Luo Y, et al. Reconstruction of temperature series of China for the last 1000 years. Chinese Sci Bull, 2007, 52: 3272-3280

14 Ren G Y, Zhang L S. Climate of the Medieval Warm Period in Maili region as inferred from fossil pollen record (in Chinese). Clim Environ Res, 1996, 1: 81-86

15 Ren G Y, Wu H, Chen Z H. Spatial pattern of change trend in rainfall of China (in Chinese). J Appl Meteorol Sci, 2000, 11: 322-330

16 Wang $\mathrm{H}$ J. The weakening of the Asian monsoon circulation after the end of 1970s. Adv Atmos Sci, 2001,18: 376-386

17 Zhao P, Zhou X J. Decadal Variability of rainfall persistence time and rainbelt shift over Eastern China in recent 40 years. J Appl Meteorol Sci, 2006, 17: 548-556

18 Zhou T, Gong D, Li J, et al. Detecting and understanding the multidecadal variability of the East Asian Summer Monsoon-Recent progress and state of affairs. Meteorol Zeitschrift, 2009, 18: 455-467

19 Zhao P, Yang S, Yu R C. Long-term changes in rainfall over eastern China and large-scale atmospheric circulation associated with recent global warming. J Clim, 2010, 23: 1544-1562

20 Tao S Y, Chen L X. A review of recent research on the East Asian summer monsoon in China. In: Chang C P, Krishnamurti T N, eds. Monsoon Meteorology. New York: Oxford University Press, 1987. 60-92

21 Webster P J. Coauthors. Monsoon: Processes, predictability, and the prospects for prediction. J Geophys Res, 1998, 103: 14451-14510

22 Chen L X, Li W, Zhao P, et al. On the process of summer monsoon onset over East Asia (in Chinese). Clim Environ Res, 2000, 5: 346-355

23 He J H, Ding Y H, Gao H, et al. Dates of Summer Monsoon Onset in the South China Sea and Monsoon Indices (in Chinese). Beijing: Chinese Meteorological Press, 2001. 1-108

24 Wang B, Lin H. Rainy season of the Asian-Pacific summer monsoon. J Clim, 2002, 15: 386-398

25 Webster P J, Yang S. Monsoon and ENSO: Selectively interactive systems. Quart J Roy Meteor Soc, 1992, 118: 877-926

26 Li C, Yanai M. The onset and interannual variability of the Asian summer monsoon in relation to land-sea interactive thermal contrast. J Clim, 1996, 9: 358-375

27 Zhao P, Zhang R H, Liu J P, et al. Onset of southwesterly wind over eastern China and associated atmospheric circulation and rainfall. Clim Dyn, 2007, 28: 797-811

28 Zhao P, Zhu Y N, Zhang R H. An Asian-Pacific teleconnection in summer tropospheric temperature and associated Asian climate variability. Clim Dyn, 2007, 29: 293-303

29 Zhao P, Chen J M, Xiao D, et al. Summer Asian-Pacific oscillation and its relationship with atmospheric circulation and monsoon rainfall. Acta Meteorol Sin, 2008, 22: 455-471

30 Zhou X J, Zhao P, Liu G. Asian-Pacific Oscillation index and variation of East Asian summer monsoon over the past millennium. Chinese Sci Bull, 2009, 54: 3768-3771

31 Zhao P, Yang S, Wang H J, et al. Interdecadal relationships between the Asian-Pacific Oscillation and summer climate anomalies over Asian, North Pacific and North America during recent 100 years. J Clim, 2011, doi: 10.1175/JCLI-D-11-00054

32 Zhou B T, Zhao P. Modeling variations of summer upper-tropospheric temperature and associated climate over the Asian-Pacific 
region during the mid-Holocene. J Geophys Res, 2010, 115: D20109, doi:10.1029/2010JD014029

33 Liu G, Zhao P, Chen J M. A 150-year reconstructed summer AsianPacific Oscillation index and its association with precipitation over eastern China. Theor Appl Climatol, 2011, 103: 239-248

34 New M, Hulme M, Jones P. Representing twentieth-century spacetime climate variability. Part I: development of a 1901-96 monthly grids of terrestrial surface climate. J Clim, 2000, $13: 2217-2238$

35 Compo G P, Whitaker J S, Sardeshmukh P D, et al. The twentieth century reanalysis project. Quart J Roy Meteorol Soc, 2011, 137, $1-28$

36 Chen F, Yuan Y J, Wei W S, et al. Correlations between the summer Asian-Pacific Oscillation index and the tree-ring width of pinus massiniana from Sha county, Fujian Province. Quat Sci, 2011, 31: 96-108

37 Zhou T, Wu B, Wen X, et al. A fast version of LASG/IAP climate system model and its 1000-year control integration, Adv Atmos Sci, 2008, 25: 655-672

38 Man W M, Zhou T J. Forced response of atmospheric oscillations during the last millennium by a climate system model. Chinese Sci Bull, 2011, 56: 3042-3052

39 Ammann C M, Joos F, Schimel D S, et al. Solar influence on climate during the past millennium: Results from transient simulations with the NCAR Climate System Model. Proc Natl Acad Sci USA, 2007, 104: 3713-3718

40 Zhou T J, Li B, Man W M, et al. A comparison of the Medieval Warm Period, the Little Ice Age and the 20th century warming simulated by the FGOALS climate system model. Chinese Sci Bull, 2011, 56: 3028-3041

41 Bard E, Raisbeck G, Yiou F, et al. Solar irradiance during the last 1200 years based on cosmogenic nuclides. Tellus B, 2000, 52:
985-992

42 Mann M E, Zhang Z, Hughes M K, et al. Proxy-based reconstructions of hemispheric and global surface temperature variations over the past two millennia. Proc Natl Acad Sci USA, 2008, 105: 1325213257

43 Qian W, Hu Q, Zhu Y, et al. Centennial-scale dry-wet variations in East Asia. Clim Dyn, 2003, 21: 77-89

44 Zhang D. The method for reconstruction of the dryness/wetness series in China for the last 500 years and its reliability. In: Zhang J C, ed. The Reconstruction of Climate in China for Historical Times. Beijing: Science Press, 1988. 18-30

45 Zhao P, Zhou Z J. An East Asian subtropical summer monsoon index and its relationship to summer rainfall in China. Acta Meteorol Sin, 2009, 23: 18-28

46 Yu R, Zhou T J. Seasonality and three-dimensional structure of the interdecadal change in East Asian monsoon. J Clim, 2007, 20: 5344-5355

47 Wu J W, Lu R J. Spatial pattern and landscape characteristics in Otindag sandy land during the Medieval Warm Period (in Chinese). J Arid Land Res Environ, 2005, 19: 110-113

48 Cao J T, Wang S M, Shen J, et al. The paleoclimate changes during the past millennium referred from the lacustrine core in Daihai Lake, Inner Mongolia. Sci Geogr Sin, 2000, 20: 391-396

49 Wu J W, Lu R J, Zhao T N. Sandy lands during the Medieval Warm Period in Eastern China. Sci Soil Water Conserv, 2004, 2: 29-33

50 Tong G B, Shi Y, Wu R J, et al. Vegetation and climate quantitative reconstruction of Longgan Lake since the past 3000 years. Mar Geol Quat Geol, 1997, 17: 54-62

51 Zhao P, Zhou X J, Liu G. Decadal-centennial-scale change in Asian-Pacific summer thermal contrast and solar activity. Chinese Sci Bull, 2011, 56: 3012-3018

Open Access This article is distributed under the terms of the Creative Commons Attribution License which permits any use, distribution, and reproduction in any medium, provided the original author(s) and source are credited. 